\title{
Annonaceae da Reserva Biológica da Represa do Grama, Descoberto, Minas Gerais, Brasil, com uma nova espécie, UNONOPSIS BAUXITAE
}

\author{
Adriana Quintella Lobão ${ }^{1,3}$, Rafaela Campostrini Forzza ${ }^{1}$ \& Renato de Mello-Silva ${ }^{2}$
}

\begin{abstract}
Resumo
(Annonaceae da Reserva Biológica da Represa do Grama, Descoberto, Minas Gerais, Brasil, com uma nova espécie, Unonopsis bauxitae) São apresentadas as espécies de Annonaceae da Reserva Biológica da Represa do Grama. A Reserva está localizada em Descoberto, Minas Gerais, e abrange uma área de 263,8 hectares de floresta estacional semidecidual. São encontrados cinco gêneros e sete espécies: Annona cacans, Guatteria nigrescens, G. sellowiana, Rollinia dolabripetala, Unonopsis bauxitae, Xylopia brasiliensis, X. sericea e a nova espécie Unonopsis bauxitae, aqui descrita. São apresentadas chave de identificação das espécies, descrições, ilustrações, e informações sobre floração, frutificação, distribuição geográfica e hábitats. Palavras-chave: Annona, Guatteria, Rollinia, Unonopsis bauxitae, Xylopia, floresta atlântica, Reserva do Grama.
\end{abstract}

\section{Abstract}

(Annonaceae of the Reserva Biológica da Represa do Grama, Descoberto, Minas Gerais, Brazil, with a new species, Unonopsis bauxitae) The Reserva Biológica da Represa do Grama is situated in Descoberto, Minas Gerais, and consists of 263.8 hectares of semideciduous forest. The following five genera and seven species of Annonaceae have been recorded from the Reserva: Annona cacans, Guatteria nigrescens, G. sellowiana, Rollinia dolabripetala, Unonopsis bauxitae, Xylopia brasiliensis, X. sericea, and the new species Unonopsis bauxitae, here described. Key for the species, descriptions, illustrations, and comments on the phenology, habitats, and distribution are included.

Key-words: Annona, Guatteria, Rollinia, Unonopsis bauxitae, Xylopia, Atlantic forest, Reserva do Grama.

\section{INTRODUÇÃo}

Há nos trópicos cerca de 130 gêneros e 2.300 espécies de Annonaceae (Kessler 1993, Koek-Noorman et al. 1997), dos quais 26 gêneros (20\%) e cerca de 260 espécies (ca. $11 \%$ ) ocorrem no Brasil (Maas et al. 2002). Aqui, a maior diversidade encontra-se na Amazônia, com um segundo centro na mata atlântica. Este trabalho apresenta as espécies de Annonaceae da Reserva Biológica da Represa do Grama, um dos poucos remanescentes de mata atlântica de Minas Gerais. Além de ser mais um trabalho florístico completo de uma família da Reserva, seguindo os Menini Neto et al. (2004), Pivari \& Forzza (2004), Almeida et al. (2005) e Assis et al. (2005), é complementar e comparativo a outros tratamentos florísticos de Annonaceae do centro-sul do Brasil (e.g. Lobão et al. 2005,
Mello-Silva 1993, 1997, Mello-Silva \& Pirani no prelo, Pontes \& Mello-Silva 2004, 2005, Stannard 1995). Apresenta, ainda, a nova espécie Unonopsis bauxitae.

\section{Material e Métodos}

A Reserva Biológica da Represa do Grama localiza-se na Serra do Relógio, Zona da Mata de Minas Gerais, no município de Descoberto $\left(21^{\circ} 25^{\prime} \mathrm{S}-42^{\circ} 56^{\prime} \mathrm{W}\right)$ e abrange uma área de 263,8 hectares de floresta estacional semidecidual montana (Menini Neto et al. 2004), a cerca de $350 \mathrm{~m}$ s.n.m. As descrições e ilustrações das espécies foram elaborad as com base nos materiais coletados na Reserva ou em material adicional de outras localidades (frutos de A. cacans e flores de $X$. brasiliensis). O tratamento de Unonopsis bauxitae traz o necessário à descrição de uma

Artigo recebido em 10/2005. Aceito para publicação em 12/2005.

${ }^{1}$ Jardim Botânico do Rio de Janeiro, Rua Pacheco Leão, 915, 22460-030 Rio de Janeiro, RJ, Brasil.

${ }^{2}$ Depto. Botânica, Universidade de São Paulo. Cx.Postal 11461. 05422-970 São Paulo, SP, Brasil. Bolsista do CNPq.

${ }^{3}$ Autor para correspondência: alobao@jbrj.gov.br 
espécie nova. A terminologia morfológica segue Radford et al. (1974). São apresentadas chave de identificação das espécies, descrições, ilustrações, e informações sobre floração, frutificação, distribuição geográfica e hábitats.

\section{Tratamento Taxonômico}

Na Reserva Biológica da Represa do Grama, a família Annonaceae está representada por cinco gêneros e sete espécies: Annona cacans, Guatteria nigrescens, G. sellowiana, Rollinia dolabripetala, Unonopsis bauxitae, Xylopia brasiliensis e X. sericea.

\section{Chave para identificação das espécies}

1. Flores supra-axilares ou opositifólias; frutos sincárpicos.

2. Pétalas externas aladas, como pás do hélice; carpídios protundentes

\section{Rollinia dolabripetala}

2. Pétalas externas não aladas; carpídios planos 1. Annona cacans

1. Flores axilares ou caulinares; frutos apocárpicos.

3. Botões estreitamente piramidais; carpídios deiscentes; sementes ariladas

4. Casca descamante, avermelhada; lâminas foliares $3-6,5 \times 0,5-1,5 \mathrm{~cm}$, face abaxial esparsamente serícea a glabra

6. Xylopia brasiliensis

4. Casca não descamante, castanha a cinérea; lâminas foliares $6,5-15 \times 2,5-4,5 \mathrm{~cm}$, face abaxial densamente serícea a glabrescente

7. Xylopia sericea

3. Botões largamente ovóides a largamente deltóides; carpídios indeiscentes; sementes não ariladas.

5. Nervura primária proeminente na face adaxial das folhas; brácteas persistentes; inflorescências rami or caulifloras, 2-10-floras; carpídios 1-5 5. Unonopsis bauxitae

5. Nervura primária impressa na face adaxial das folhas; brácteas caducas; flores axilares, solitárias; carpídios 20-50.

6. Lâminas foliares 8,5-20 × 2-6 cm; pétalas externas $15-20 \times 5-12 \mathrm{~mm}$, internas $20-$ $30 \times 9-10 \mathrm{~mm}$

2. Guatteria nigrescens

6. Lâminas foliares 5,5-11 × 1,5-3 cm; pétalas externas 6-13 × 4-5 mm, internas 7-13 $\times 5-7 \mathrm{~mm}$

3. Guatteria sellowiana

\section{Annona L.}

Árvores, arvoretas ou arbustos. Tricomas simples ou estrelados. Folhas com nervura primária impressa na face adaxial, domácias presentes ou ausentes. Flores solitárias ou em inflorescência, monoclinas, raramente diclinas; sépalas 3, livres ou conatas; pétalas 6 , raramente 3 , livres ou conatas na base, as externas valvares, as internas valvares ou imbricadas; estames numerosos, conectivo dilatado em forma disco, raramente apiculado ou semi-orbicular, anteras não septadas transversalmente; carpelos numerosos, óvulo 1, basal. Fruto sincárpico, carnoso, indeiscente; sementes muitas, sem arilo.

Annona possui aproximadamente 110 espécies neotropicais e quatro africanas (Heusden 1992; Kessler 1993). Algumas são cultivadas pelos frutos comestíveis.
1. Annona cacans Warm., Vidensk. Meddel. Dansk Naturhist. Foren. Kjöbenhavn 3(5): 155. f. 1-2. 1873.

Fig. 1 a-c

Árvore 7-20 m alt. Ramos jovens glabrescentes, in sicco alaranjados, ramos adultos glabros, lenticelados. Pecíolo 13-15 mm compr., canaliculado. Lâmina foliar 6-17 $\times 2-4 \mathrm{~cm}$, cartácea, estreitamente-elíptica a elíptica, glabra; base atenuada; margem plana; ápice agudo; nervação broquidódroma, amarelada, 12-15 pares de nervuras secundárias levemente arqueadas, juntamente com o retículo proeminente em ambas as faces; domácias ausentes. Flores 1-2, opositifolias; botões ovóide-acuminados; pedicelos 5-8 mm compr.; brácteas persistentes; sépalas ca. $2 \times$ $3 \mathrm{~mm}$, conatas na base, largamente triangulares, esparsamente tomentosas na face 
abaxial, glabras na adaxial; pétalas conatas na base, as externas ca. $7 \times 6 \mathrm{~mm}$, largamente ovais, não aladas, creme a amareladas, avermelhadas na base, tomentosas na face adaxial, esparsamente tomentosas na abaxial, as internas ca. $6 \times 3 \mathrm{~mm}$, oval-triangulares, creme a alvas, avermelhadas na face adaxial, tomentosas em ambas as faces; estames ca. 1,5 mm compr.; carpelos ca. $1 \mathrm{~mm}$ compr., glabros. Frutos ca. 3,5 × 3,5 cm, largamente ovóides, carpídios planos, verde-glaucos.

Material examinado: 8.III.2003, fr., L. C. S. Assis et al. 730 (CESJ); 10.IX.2001, fl., G. Augustin et al. s.n. (CESJ 35079, RB); 30.XI.2001, fl., D. Pifano \& R. M. Castro 186 (CESJ).

Material adicional selecionado: BRASIL. ESPÍRITO SANTO: Santa Teresa. 13.II.1999, fr., R. Mello-Silva et al. 1573 (K, MBM, MBML, RB, SPF).

\section{Nome popular: Araticum}

Annona cacans ocorre da Bahia ao Rio Grande do Sul, seguindo a distribuição da floresta atlântica sensu lato (Rainer 2001). Foi coletada em flor em novembro e em fruto em março. Éutilizada como ornamental e a poupa dos frutos é comestível (Corrêa 1984).

\section{Guatteria Ruiz \& Pav.}

Árvores, arvoretas ou arbustos. Tricomas simples. Folhas com nervura primária impressa na face adaxial. Flor em geral solitária ou em inflorescência, monoclinas; pedicelo articulado, brácteas presentes abaixo da articulação; sépalas 3, livres ou conatas no botão; pétalas 6, livres, imbricadas; estames numerosos, conectivo dilatado no ápice, em forma de disco truncado, às vezes umbonado, anteras não septadas transversalmente; carpelos numerosos, óvulo 1, basal. Fruto apocárpico, carpídios em geral estipitados, indeiscentes; semente 1 , sem arilo.

Guatteria é o maior gênero da família com cerca de 260 espécies e o que apresenta os maiores problemas taxonômicos. É neotropical, ocorrendo da América Central ao sul do Brasil (Maas et al. 1994).
2. Guatteria nigrescens Mart. in Mart., Fl. bras. 13(1): 31. 1841 Fig. $1 \mathrm{~d}$ $\mathrm{e}$

Árvore ou arvoreta, 3-7 m alt. Ramos jovens vilosos, lenticelados ou não, ramos adultos glabros. Pecíolo 5-10 mm compr., levemente canaliculado, com fissuras transversais. Lâmina foliar 8,5-20 × 2-6 cm, cartácea, estreitamente elíptica ou estreitamente obovada, verde, discolor, glabra na face adaxial, esparsamente serícea a glabra na abaxial; base atenuada a decurrente; margem plana;ápice cuspidado, cúspide 7-10 mm compr.; nervação broquidódroma, 13-24 pares de nervuras secundárias, juntamente com o retículo, proeminentes em ambas as faces. Flor 1, axilar; botões triangular-ovóides; pedicelo 3-6,5 cm compr.; brácteas caducas; sépalas 5-7 × 5-7 $\mathrm{mm}$, largamente triangulares, valvares, glabras na base e vilosas no ápice da face abaxial, vilosa na adaxial; pétalas ovais, ápice agudo, verde-claras a amareladas, quando maduras levemente avermelhadas, vilosas na face adaxial, glabras na base da adaxial, as externas $15-20 \times 5-12$ $\mathrm{mm}$, as internas $20-30 \times 9-10 \mathrm{~mm}$; estames ca. $2 \mathrm{~mm}$ compr.; carpelos ca. $3 \mathrm{~mm}$ compr., seríceos. Carpídios 20-50, 10-12 ×5 mm, elipsóides, estipes 8-17 mm compr., vermelhopurpúreos, glabros.

Material examinado: $2 . X I .2002$, fl., L. C. S. Assis et al. 606 (CESJ, RB); 11.IX.2003, fr., $L$. C. S. Assis et al. 883, 884, 887 (CESJ, RB); 30.I.2004, fl., L. C. S. Assis et al. 939, 944 (CESJ, RB, SPF); 9.VI.2001, fr., R. M. Castro et al. 465 (CESJ, RB); 7.VII.2001, fr., R. M. Castro et al. 515 (CESJ, RB); 10.IX.2001, fr., P. C. L. Faria et al. s.n. (CESJ 34484, RB); 26.XI.2000, fl., $R$. C. Forzza \& L. Meireles 1717 (CESJ, RB, SPF); 12.I.2002, fl., R. C. Forzza et al. 2030 (CESJ, RB); 30.XI.2001, fl., D. Pifano \& R. M. Castro 196 (CESJ, RB); 1.XII.2001, fl., D. Pifano et al. 207 (CESJ, RB, SPF); 16.I.2000, fl., F. $R$. Salimena et al. s.n. (CESJ 31013, SPF); 8.VIII.2000, fr., F. R. Salimena et al. s.n. (CESJ 31397, SPF); 25.V.2000, fr., P. C. Zampa et al. s.n. (CESJ 31173, SPF). 


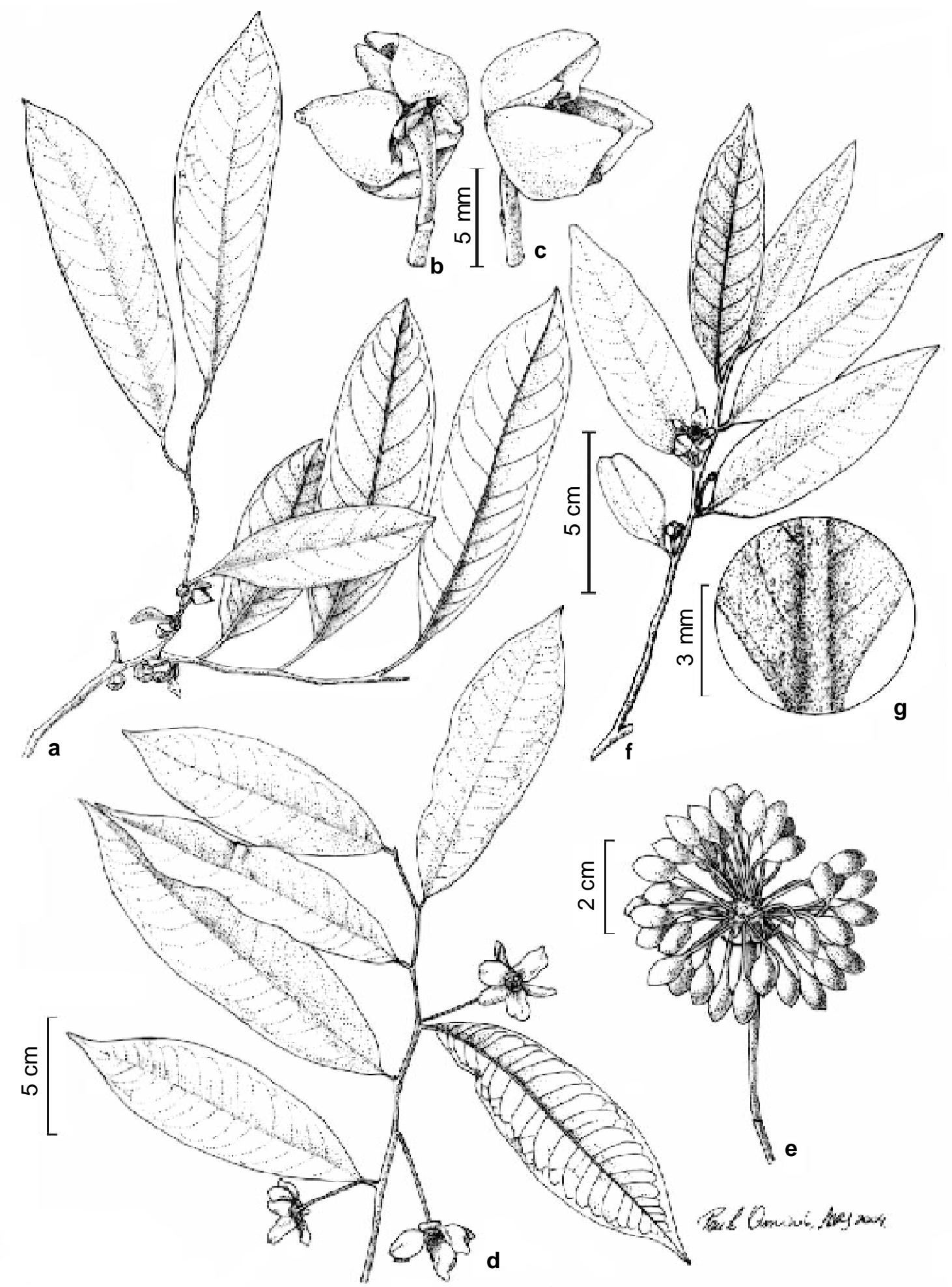

Figura 1 - a-c. Annona cacans. a. Ramo com botões e flores; b. flor, vistadorsal, evidenciando bráctea, sépalas e pétalas externas; c. flor, vista lateral, evidenciando pétalas externas. d-e. Guatteria nigrescens. d. Ramo com flores; e. fruto. f-g. Guatteria sellowiana. f. Ramo com botão e flor; g. detalhe do indumento da face abaxial da folha. (a-c Augustin s.n. (CESJ 35079); d Castro 515; e Forzza 2030; f, g Castro 501). 
Nome popular: Pindaíba-negra

Guatteria nigrescens distribui-se na floresta atlântica de Minas Gerais, Rio de Janeiro e São Paulo (Lobão 2003). Na Reserva é a espécie mais freqüiente de Annonaceae, ocorrendo próximo a cursos d'água e locais alagados. Foi coletada em flor de setembro a janeiro e em fruto de maio a setembro e em novembro.

3. Guatteria sellowiana Schltdl., Linnaea 9: 323. 1835. Fig. $1 \mathrm{f}-\mathrm{g}$

Árvore ou arvoreta, 5-8 m alt. Ramos tomentosos. Pecíolo 3-5 mm compr., levemente canaliculado, com fissuras transversais, tomentosos. Lâmina foliar 5,5$11 \times 1,5-3 \mathrm{~cm}$, cartácea, estreitamente elíptica, verde, esparsamente tomentosa na face adaxial, densamente tomentosa na abaxial, base atenuada, margem plana, ápice agudo, nervação broquidódroma, ca. 20 pares de nervuras secundárias, juntamente com o retículo, proeminentes em ambas as faces. Flor 1, axilar; botões triangular-ovóides; pedicelo 0,5-1 cm compr; brácteas caducas; sépalas 4-7 × 3-7 mm, valvares, largamente triangulares, tomentosas em ambas as faces; pétalas ovais, esverdeadas, ápice acuminado, as externas 6-13 × 4-5 $\mathrm{mm}$, densamente tomentoso-vilosas em ambas as faces, as internas 7-13 × 5-7 mm, glabras na base e tomentosas no ápice da face adaxial, tomentosas na abaxial; estames ca. $1 \mathrm{~mm}$ compr.; carpelos ca. $2 \mathrm{~mm}$ compr., seríceos. Carpídios 20-50, 10-12 ×5 mm, elipsóides, estipes 8-17 mm compr., vermelho-purpúreos, glabros.

Material examinado: 7.VII.2001, fl., $R$. $M$. Castro etal. 501 (CESJ, RB, SPF);21.VII.2001, fl., R. M. Castro 562 (CESJ, SPF).

Guatteria sellowiana ocorre na Bahia, Goiás, Minas Gerais, Distrito Federal, Espírito Santo e Rio de Janeiro (Maas et al. 2002). É comum nas matas de galeria do Brasil central. $\mathrm{Na}$ Reserva é pouco frequiente e foi coletada em flor em julho.
Rollinia A. St.-Hil.

Árvores, arvoretas ou arbustos. Tricomas simples, raramente furcados ou estrelados. Folhas com nervura primária impressa na face adaxial. Flor solitária ou em inflorescência, supra-axilar, opositifolia ou raramente subaxilar; sépalas 3, livres; pétalas 6 , conatas na base, as externas aladas, as internas muito menores; estames numerosos, anteras não septadas transversalmente; carpelos numerosos, óvulo 1, basal. Fruto sincárpico, raramente apocárpico, carpídios indeiscentes; sementes muitas quando sincárpico e 1 por carpídio quando apocárpico, sem arilo.

Rollinia ocorre do México ao norte da Argentina e possui aproximadamente 44 espécies distribuídas em dois centros de diversidade. O principal, na Amazônia, conta com cerca de 25 espécies e o secundário, na costa leste do Brasil, conta com cerca de 14 espécies (Maas \& Westra 1992).

4. Rollinia dolabripetala (Raddi) R. E. Fr., Kongl. Svenska Vetenskapsakad. Handl., n.s., 34(5): 45. 1900.

Fig. 2 a-c 319. 1835.

Rollinia laurifolia Schltdl., Linnaea 9:

Árvore ou arvoreta ou 2-7 m alt. Ramos jovens seríceos, ramos adultos glabros, lenticelados. Pecíolo 8-12 mm compr. Lâmina foliar 8-16(-24) × 2-5(-8) cm, cartácea a subcoriácea, estreitamente elíptica, glabra na face adaxial, esparsamente setosas na abaxial; base aguda, às vezes obtusa e assimétrica, margem plana, ápice agudo, nervação broquido-camptódroma, ca. 20 pares de nervuras secundárias, juntamente com o retículo, pouco proeminentes em ambas as faces. Flores 1-3, supra-axilares ou opositifolias; pedicelo 13-30 mm compr., tomentoso; brácteas caducas; sépalas ca. $2 \times$ $4 \mathrm{~mm}$, depresso-triangulares, tomentosa na face abaxial, glabras na adaxial; pétalas creme a esverdeadas, as externas $8-20 \times 5-6 \mathrm{~mm}$, oblongo-clavadas, aladas, tubo da corola ca. 3 $\mathrm{mm}$ compr., alas $13 \times 6 \mathrm{~mm}$, as internas 


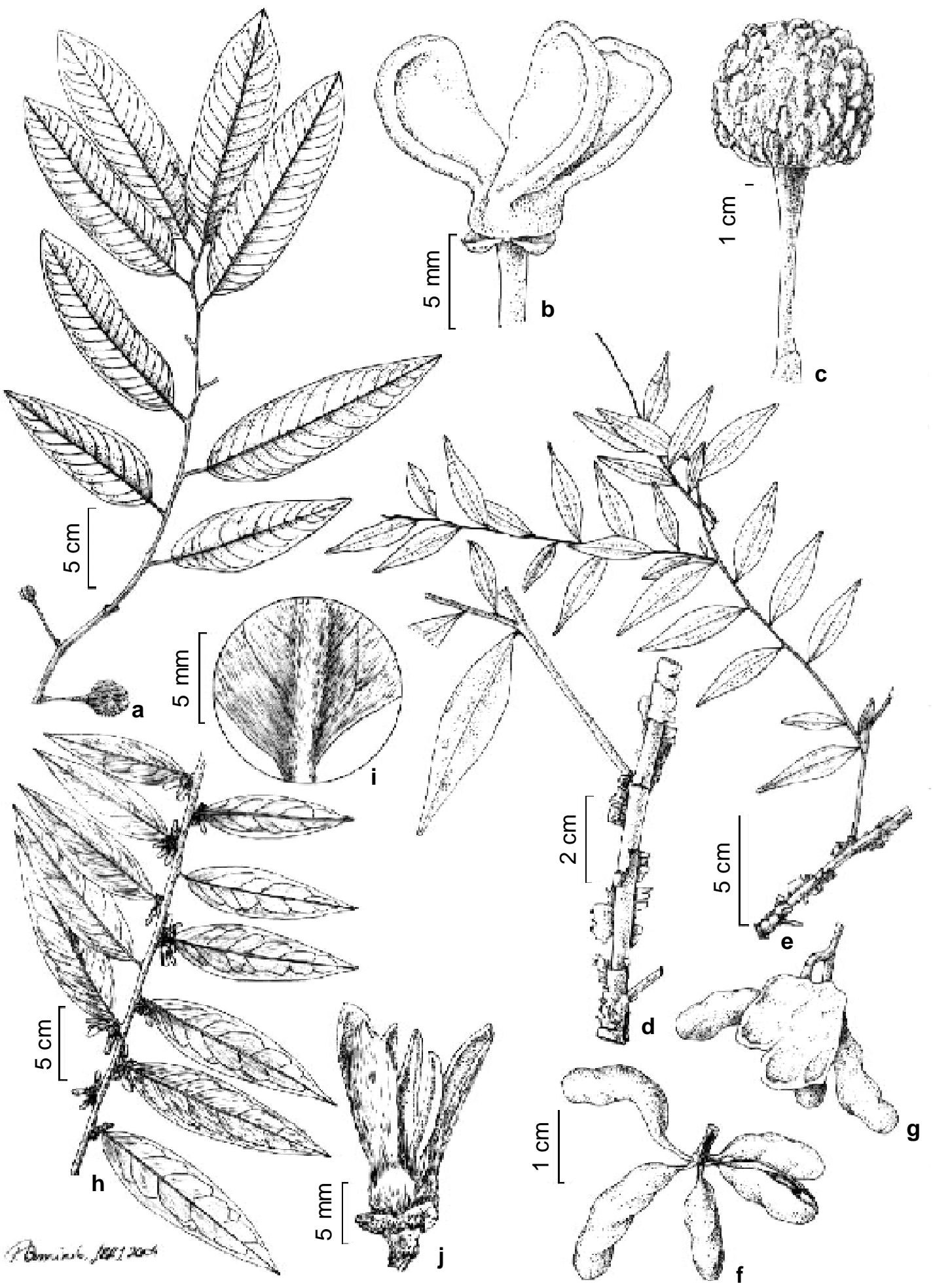

Figura 2 - a-c. Rollinia dolabripetala. a. Ramo comfrutos jovens; b. Flor evidenciando pétalas externas aladas; c. Fruto maduro. d-g. Xylopia brasiliensis. d. Ramo evidenciando o ritidoma descamante; e. Ramo; f. fruto com carpídios fechados; g. Fruto com carpídio aberto. h-j. Xylopia sericea h. Ramo com botões e flores; i. detalhe do indumento da face abaxial da folha; j. flor evidenciando pétalas externas e internas. (a,c Assis 741; b Castro 673; d-g Forzza 2241; h-j Pífano 200). 
estreitamente triangulares ca. $15 \times 3 \mathrm{~mm}$, menores que as externas; estames ca. $1 \mathrm{~mm}$ compr.; carpelos ca. $2 \mathrm{~mm}$ compr., seríceos na base. Frutos sincárpicos, largamente ovóides, 2-2,5 × 2-2,5 cm, carpídios 40-60, mais ou menos oblongos, apiculados, verdes passando a amarelos quando maduros.

Material examinado: 9.III.2003, fr., L. C. S Assis et al. 741 (CESJ, RB); 11.II.2001, fr., R. M. Castro et al. 106 (CESJ, RB, SPF); 7.VII.2001, fr., R. M. Castro et al. 507 (CESJ); 30.XI.2001, fl., R. M. Castro \& D. Pifano 673 (CESJ, RB, SPF); 10.X.2002, fl., P. C. L. Faria \& B. Antunes 89 (CESJ, RB); 12.I.2002, fr., R. C. Forzza et al. 2032 (CESJ).

Rollinia dolabripetala ocorre de Santa Catarina à Bahia (Mello-Silva 1997), e no Distrito Federal (Pontes \& Mello-Silva 2004). $\mathrm{Na}$ Reserva é muito comum, em geral, em áreas bem drenadas da floresta de encosta. Foi coletada em flor em novembro e em fruto de janeiro a março, maio e julho.

Coleções de $R$. dolabripetala, principalmente da mata atlântica de Minas Gerais, têm sido identificadas como $R$. laurifolia, mas a sinonimização das duas espécies é proposta por Mello-Silva \& Pirani (no prelo).

\section{Unonopsis R. E. Fr.}

Árvores ou arbustos. Tricomas simples. Folhas con nervura primária proeminente na face adaxial. Flor solitária ou em inflorescências, axilares ou caulinares, monoclina; sépalas 3 , livres ou conatas, valvares; pétalas 6 , livres, valvares; estames numerosos, anteras não septadas transversalmente; carpelos numerosos, óvulos 1-8, marginais. Fruto apocárpico, carpídios indeiscentes; semente 1(-2-5), sem arilo.

Unonopsis possui cerca de 40 espécies, muitas ainda não descritas (Maas et al. 2002). Ocorre da América Central e Antilhas ao sudeste do Brasil (Steyermark et al. 1995).
5. Unonopsis bauxitae Maas, Westra \& Mello-Silva, sp. nov. Tipo: BRASIL. MINAS GERAIS: Descoberto, Reserva Biológica da Represa do Grama, 9.XII.2001, fl. e fr., R.M. Castro et al. 745 (holótipo SPF 3 exsicatas; isótipos BHCB, CESJ 2 exsicatas, K, NY, RB, $\mathrm{U})$.

Fig. 3 a-f

Unonopsi riedelianae proxima sed foliis majoribus et latioribus et alabastris acutis vel acuminatis nec obtusis differt.

Árvore, 7-17 m alt. Ramos glabrescentes Pecíolo 3-7 mm compr., semi-cilíndrico, plano na face adaxial. Lâmina foliar 14-19 × 4-6 $\mathrm{cm}$, cartácea a subcoriácea, estreitamente elíptica, simétrica a levemente assimétrica, in sicco castanha, glabra exceto nervura central da face abaxial pubescente e glabrescente, base aguda, margem plana, ápice acuminado, acúmem 5-25 mm compr., às vezes agudo, nervação eucamptódroma na metade proximal e broquidódroma na distal, 10-15 pares de nervuras secundárias proeminentes em ambas as faces, mais na abaxial, retículo impresso na face adaxial, proeminente na abaxial. Inflorescências ramifloras, ramos $1-7 \times 5-10$ $\mathrm{mm}, 2-10$-floras; botões 3-10 × 3-9 mm, depresso-ovóides, acuminados ou agudos; pedicelo 10-25 mm compr., áureo-adpressopubescente; brácteas depresso a largamente ovadas, 1-2 mm compr., adpressopubescentes, persistentes; sépalas depressoovado-triangulares, $1-1,5 \times 3 \mathrm{~mm}$, conatas, glabras na face adaxial, áureo-adpressopubescentes na abaxial; pétalas carnosas, as externas 8-14 × 5-10 mm, oval-triangulares, acuminadas, planas, glabras na face adaxial, áureo-adpresso-seríceas na abaxial, as internas 6-9 × 4-8 mm, ovais, cuculadas, áureoadpresso-seríceas sobre a nervura central da face abaxial, restante glabra; receptáculo truncado, estames ca. $1 \mathrm{~mm}$ compr.; carpelos 25-50, 1-2 mm compr., densamente áureoseríceos, óvulo basal. Carpídios 1-5, 15-25× 10-20 mm, elipsóides a obovóides, imaturos verdes, áureo-pubérulos, estipes 10-15 mm 
compr., receptáculo na frutificação depresso a largamente ovóide, $2-4 \times 3-5 \mathrm{~mm}$, densamente adpresso-áureo-seríceo. Sementes não vistas.

Parátipo: BRASIL. MINAS GERAIS: Descoberto, Reserva Biológica da Represa do Grama, 22.IX.2002, f1., R. C. Forzza et al. 2222 (CESJ, MBM, MO, RB, SPF, U).

Unonopsis bauxitae é provavelmente próxima de $U$. riedeliana, da qual difere pelas folhas maiores e mais espessas e pelos botões acuminados. Os frutos de $U$. riedeliana são desconhecidos e $U$. bauxitae possui os maiores frutos conhecidos dentre as Unonopsis do sudeste do Brasil. É a única espécie de Unonopsis da mata atlântica de Minas Gerais. A outra espécie que também ocorre em Minas Gerais, U. lindmanii, habita matas cilares do sudeste de Goiás e oeste de Minas Gerais, São Paulo e Paraná, no domínio dos cerrados. Na mata atlântica, há ainda, $U$. riedeliana, endêmica de Petrópolis, Rio de Janeiro, e quatro ou cinco espécies ainda não descritas, de Rio das Ostras, no Rio de Janeiro, de Linhares e Santa Teresa, no Espírito Santo, e do sul da Bahia (Maas et al. 2002). Unonopsis bauxitae é endêmica da Reserva do Grama. Ocorre exclusivamente numa mata semi-caducifólia que medra sobre afloramentos de bauxita.

\section{Xylopia $\mathrm{L}$.}

Árvores ou arbustos. Tricomas simples. Folhas com nervura primária impressa na face adaxial. Flores axilares, monoclinas; botão estreitamente piramidal; sépalas 3, conatas na base, valvares, raramente imbricadas; pétalas 6, livres, valvares, as internas menores; estames e estaminódios numerosos, anteras septadas transversalmente, ápice do conectivo dilatado, truncado; carpelos poucos a muitos, óvulos 2-8, marginais. Fruto apocárpico, carpídios em geral estipitados, deiscentes; sementes com arilo.

Xylopia é pantropical e possui entre 100160 espécies (Kessler 1993).
6. Xylopia brasiliensis Spreng., Neue Entd. 3: 50.1822.

Fig. 2 d-g

Árvore, 3-6m alt. Ramos jovens glabrescentes, ramos adultos glabros, ferrugíneos; ritidoma descamante, avermelhado. Pecíolo 1 $3 \mathrm{~mm}$ compr. Lâmina foliar 3-6,5 × 0,5-1,5 $\mathrm{cm}$, cartácea, estreitamente elíptica, glabra na face adaxial, esparsamente serícea a glabra na abaxial; base atenuada; margem inteira; ápice acuminado; nervação broquidódroma, ca. 10 pares de nervuras secundárias ligeiramente arqueadas, juntamente com o retículo, pouco proeminentes em ambas as faces. Flores 1-3, axilares; botões estreitamente piramidais; pedicelo ca. $4 \mathrm{~mm}$ compr.; brácteas persistentes, ápice bilobado; sépalas ca. 2,5× $2,5 \mathrm{~mm}$, conatas na base, largamente triangulares, seríceas na face abaxial, glabras na adaxial; pétalas avermelhadas, as externas $22 \times 4 \mathrm{~mm}$, estreitamente oblongas, dilatadas na base, vilosas na face abaxial, vilosas no ápice da abaxial, as internas ca. $19 \times 1,5 \mathrm{~mm}$, menores que as externas, lineares, esparsamente vilosas na face adaxial, seríceas na abaxial; estames ca. 1,5 mm compr.; estaminódios presentes entre os estames e os carpelos; carpelos ca. $6 \mathrm{~mm}$ compr., seríceos na base. Carpídios 4-9, 10-20 × 5-7 mm, clavado-falcados, apiculados, verdes, glabrescentes, estipes ca. $3 \mathrm{~mm}$ compr. Sementes 2-5.

Material examinado: 23.IX.2002, fr., R.C. Forzza et al. 2241 (CESJ, RB, SPF).

Material adicional selecionado: BRASIL. RIO DE JANEIRO: Itatiaia, lotes 28-30, XII.1918, P. Campos Porto 852 (RB). Nova Friburgo, Reserva Ecológica Municipal de Macaé de Cima, $22^{\circ} 00^{\prime} S$ 42 $03^{\circ} \mathrm{W}$, elev. 1200 m, 27.XII.1989, fl., M. Nadruz et al. 526 (RB). Rio de Janeiro, Corcovado, 26.XII.1920, fl., A. Ducke \& J. G. Kuhlmann s.n. (RB 15388); Jacarepaguá, Açude do Camorim, 3.I.1933, fl., J. G. Kuhlmann s.n. (RB 306). SÃOPAULO. Serviço Florestal de São Paulo, V.1945, fl., J. I. Lima s.n. (RB 54295).

Nome popular: Casca-de-barata 


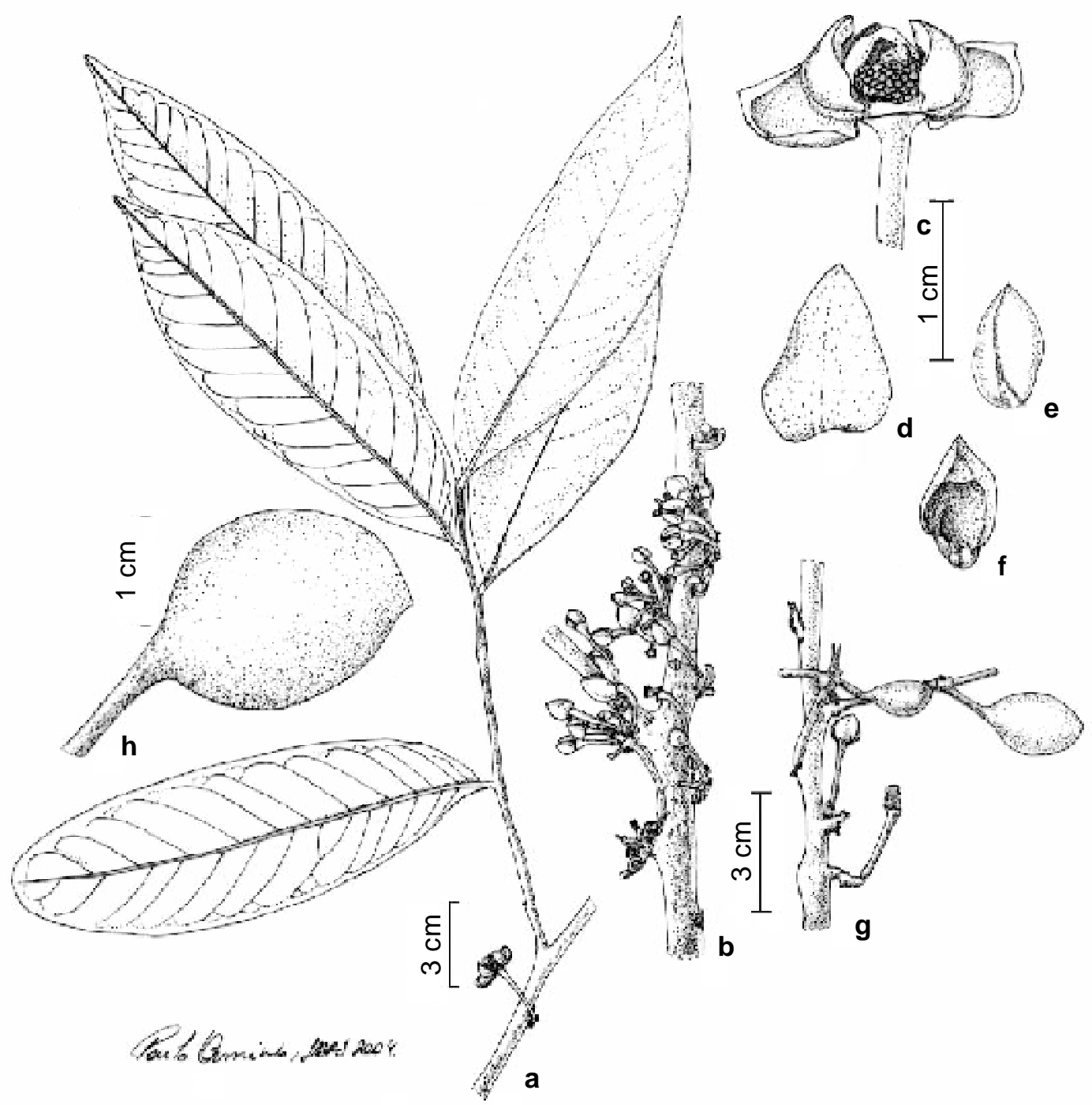

Figura 3 - a-f Unonopsis bauxitae Maas, Westra \& Mello-Silva. a. Ramo com flor madura; b. ramo caulinar evidenciando as flores; c. flor com uma das pétalas externas removida; d. pétala externa, face abaxial; e. Pétala interna, face abaxial; f. Pétala interna, face adaxial; g. ramo com botão floral e frutos; h. fruto. (a, c-h Castro 745; b Forzza 2222).

Xylopia brasiliensis caracteriza-se pelo ritidoma descamante, que the confere o nome popular "casca-de-barata", pelas folhas de pequenas dimensões, e flores avermelhadas. Ocorre no Brasil, de Minas Gerais a Santa Catarina, e no Paraguai(Dias 1988; Fries 1930; Maas et al. 2002). Na Reserva há diversos indivíduos jovens, em locais úmidos, mas indivíduos adultos são raros. Foi coletada em fruto em setembro.
7. Xylopia sericea A. St.-Hil., Fl. Bras. merid. 1(2): 41. 1825.

Fig. 2 h-j

Árvore 10-13 m alt. Ramos jovens áureo-seríceos, ramos adultos glabrescentes a glabros, lenticelados; ritidoma íntegro, acastanhado. Pecíolo 5-7 mm compr. Lâmina foliar $6,5-15 \times 2,5-4,5 \mathrm{~cm}$, estreitamente elíptica, subcoriácea a cartácea, glabra na face adaxial, densamente serícea a glabrescente na abaxial; base aguda a obtusa; margem plana a pouco revoluta; ápice acuminado; nervação broquidódroma, ca. 8 pares de nervuras 
secundárias ligeiramente arqueadas, juntamente com o retículo, pouco proeminentes em ambas as faces. Flores 1-7, axilares, subsésseis. Brácteas persistentes, ápice bilobado; botões estreitamente piramidais, seríceos; sépalas ca. $3 \times 3 \mathrm{~mm}$, largamente triangulares, seríceas na face abaxial, glabras na adaxial; pétalas alvas, as externas 14-15x 3-4 mm, estreitamente oblongas, dilatadas na base, glabras na base e tomentosas no ápice da face adaxial, áureo-seríceas na abaxial, as internas ca. $13 \times 2 \mathrm{~mm}$, lineares, tomentosas em ambas as faces; estames ca. 1,5 mm compr.; estaminódios presentes entre os estames e os carpelos; carpelos ca. $4 \mathrm{~mm}$ compr., seríceos na base. Carpídios 2-9, 13$23 \times 10-12 \mathrm{~mm}$, clavado-falcados, não apiculados, castanho-avermelhados, glabrescentes, subsésseis. Sementes (1-)2-3. Material examinado: 7.V.2001, fr., $R$. $M$. Castro et al. 307 (CESJ); 30.XI.2001, fl., D. Pifano \& R. M. Castro 200 (CESJ, RB); 13.V.2000, fr., F. R. Salimena et al. s.n. (CESJ 31172, SPF).

Nome popular: Pimenteira-de-macaco

Xylopia sericea ocorre da Colômbia ao Estado do Paraná, no Brasil (Dias 1988; Fries 1930; Steyermark et al. 1995) numa grande variedade de hábitats. Fornece madeira própria para mastros de pequenas embarcações, as fibras da casca são usadas na indústria caseira de cordoaria e a árvore pode ser ornamental (Corrêa 1984). Na Reserva é muito freqüente em locais mais secos, formando grandes adensamentos. As sementes são utilizadas como substituto de pimentas. Foi coletada em flor em novembro e em fruto em maio e junho.

\section{REFERÊNCIAS BibliográficaS}

Almeida, V. R.; Temponi, L.G. \& Forzza, R. C. 2005. A família Araceae na Reserva Biológica da Represa do Grama, Descoberto, Minas Gerais, Brasil. Rodriguésia 56(88): 127-144.

Assis, L. C. S.; Forzza, R. C. \& Werff, H. van der. 2005. A família Lauraceae na Reserva Biológica da Represa do Grama,
Descoberto, Minas Gerais, Brasil. Boletim de Botânica da Universidade de São Paulo 23(1): 113-139.

Corrêa, M. P. 1984. Dicionário das plantas úteis do Brasil e das exóticas cultivadas. Imprensa Nacional, Rio de Janeiro, vol. 1-6.

Dias, M. C. 1988. Estudos taxonômicos do gênero Xylopia L. (Annonaceae) no Brasil extra-amazônico. Dissertação de Mestrado. Universidade Estadual de Campinas. Campinas.

Fries, R. E. 1930. Revision der Arten einiger Anonaceen-Gattungen. I. Acta Horti Bergiani 10(1): 1-128.

Heusden, E. C. H. van. 1992. Flowers of Annonaceae: morphology, classification, and evolution. Blumea 7: 1-218.

Kessler, P. J. A. 1993. Annonaceae. In: K. Kubitzki., J. C. Rohwer \& V. Bittrich (eds.) The families and genera of vascular plants II: Flowering plants. Dicotyledons. Magnoliid, Hamamelid and Caryophyllid families. Springer-Verlag, Berlin, p. 93129.

Koek-Noorman, J.; Setten, A. K. van \& Kuilen, C. M. van 1997. Studies in Annonaceae. XXVI. Flowers and fruit morphology in Annonaceae. Their contribution to patterns in cluster analysis. Botanische Jahrbücher für Systematik 119(2): 213-230.

Lobão, A. Q. 2003. Guatteria (Annonaceae) do Estado do Rio de Janeiro. Dissertação de Mestrado. Universidade de São Paulo. São Paulo.

Lobão, A. Q.; Araujo, D. S. D. \& Kurtz, B. C. 2005. Annonaceae das Restingas do Estado do Rio de Janeiro, Brasil. Rodriguésia 56(87): 85-96.

Maas, P. J. M.; Maas-van de Kamer, H.; Junikka, L.; Mello-Silva, R. \& Rainer, H. 2002 (“2001"). Annonaceae of eastern and south-eastern Brazil. Rodriguésia 52(80): 61-94. 
Maas, P. J. M.; Mennega, E. A. \& Westra, L. Y. T. 1994. Studies in Annonaceae XXI. Index to species and infraspecific taxa of neotropical Annonaceae. Candollea 49(2): 389-481.

Maas, P. J. M. \& Westra, L. Y. T. 1992. Rollinia. Flora Neotropica Monograph 57: 1-188.

Mello-Silva, R. 1993. Annonaceae. Flora Fanerogâmica da Ilha do Cardoso 3: 4351.

Mello-Silva, R. 1997. Annonaceae. In: M. C. M. Marques (ed.) Mapeamento da cobertura vegetal e listagem das espécies ocorrentes na área de proteção ambiental de Cairuçu, Município de Parati, RJ. Jardim Botânico do Rio de Janeiro, Rio de Janeiro, p. 52-53.

Mello-Silva, R. \& Pirani, J. R. no prelo. Flora da Serra do Cipó, Minas Gerais: Annonaceae. Boletim de Botânica da Universidade de São Paulo 24.

Menini Neto, L.; Almeida, V. R. \& Forzza, R. C. 2004. A família Orchidaceae na Reserva Biológica da Represa do Grama, Descoberto, Minas Gerais, Brasil. Rodriguésia 55(84): 137-156.

Pivari, M. O. \& Forzza, R. C. 2004. A família Palmae na Reserva Biológica da Represa do Grama, Descoberto, Minas Gerais, Brasil. Rodriguésia 55(85): 115-124.
Pontes, A. F. \& Mello-Silva, R. 2004 ('2003”). Annonaceae. In: T. B. Cavalcanti \& A. E Ramos (eds.) Flora do Distrito Federal, Brasil. Embrapa Recursos Genéticos e Biotecnologia, Brasília, 3: 21-48.

Pontes, A. F. \& Mello-Silva, R. 2005. Annonaceae do Parque Nacional da Serra da Canastra, Minas Gerais, Brasil. Boletim de Botânica da Universidade de São Paulo 23(1): 71-84.

Radford, A. E.; Dickison, W. C.; Massey, J. R. \& Bell, C. R. 1974. Vascular plant systematics. Harper \& Row, New York, 891p.

Rainer, H. 2001. Nomenclatural and taxonomic notes on Annona (Annonaceae). Annalen des Naturhistorischen Museums in Wien 103B: 513-524.

Steyermark, J; Maas, P. J. M.; Berry, P.; Johnson, D. M.; Murray, N. A. \& Rainer, H. 1995. Annonaceae. In: P. E. Berry, B. K. Holst, \& K. Yatskievych (eds.) Flora of the Venezuelan Guayana. Timber Press, Portland, 2: 413-462.

Stannard, B. L. 1995. Annonaceae. In: B. L. Stannard (ed.) Flora do Pico das Almas, Chapada Diamantina, Bahia, Brazil. Royal Botanic Gardens, Kew, p. 126-128. 
